\title{
The Effects of a 36-Hour Mixed Task Ultraendurance Race on Mucosal Immunity Markers and Pulmonary Function
}

\author{
David Bellar, PhD; Kellie A. Murphy, MS; Ritvik Aithal, BS; Greggory R. Davis, PhD; Tim Piper, MS \\ From the School of Kinesiology, University of Louisiana at Lafayette, Lafayette, LA (Drs Bellar, Aithal, and Davis, and Ms Murphy); and the \\ Department of Kinesiology, Western Illinois University, Macomb, IL (Mr Piper).
}

\begin{abstract}
Objective.-The present study was conducted to assess the changes in mucosal immunity and pulmonary function among participants in a 36-hour mixed task ultraendurance race.

Methods. - Thirteen of the 20 race participants volunteered for the investigation (age $34 \pm 5 \mathrm{y}$ ). The event consisted of a mixture of aerobic, strong man, and military-style exercise. Participants had a pulmonary function test and gave a finger stick capillary blood sample and unstimulated saliva samples both before the event and upon dropout or completion. The blood sample was analyzed for hematocrit, and the saliva sample was analyzed for salivary flow rate, salivary alpha amylase, salivary immunoglobulin A (IgA), and $\operatorname{IgA}$ type 1.

Results.-Significant differences were noted among the finishers and those who dropped out in salivary flow rate $(P=.026)$, salivary $\operatorname{IgA}(P=.017)$, and peak expiratory flow $(P=.05)$ measurements. Salivary flow rate and $\operatorname{IgA}$ for the race finishers were reduced from pre- to postrace, whereas the nonfinishers showed no change or small increases. No significant differences emerged for other variables.

Conclusions.-Based on the results of the present investigation, finishing a 36-hour mixed task ultraendurance event results in a decline in both pulmonary function and mucosal immunity compared with competitors who do not finish.
\end{abstract}

Keywords: mucosal immunity, peak expiratory flow, salivary $\operatorname{IgA}$, alpha amylase

\section{Introduction}

Ultraendurance events are races that last for $>6$ hours and up to several days. Participation in these events is growing, as is analysis of performance trends in those who finish these lengthy efforts. ${ }^{1-3}$ According to the International Association of Ultrarunners (http://iau-ultra marathon.org), hundreds of these races are hosted each year. These events offer a unique opportunity to examine physiologic changes when the body is subjected to longterm physical stress and possibly sleep deprivation. Although there is great variability in the structures of these competitions, participation results in similar

Corresponding author: David Bellar, $\mathrm{PhD}$, University of Louisiana at Lafayette, 225 Cajundome Blvd., Lafayette, LA 70506; e-mail: dmb1527@louisiana.edu.

Partial results presented at the 2014 ACSM National Conference, May 27-31, 2014, Orlando, FL.

Submitted for publication May 2016.

Accepted for publication December 2016. physiologic ${ }^{4-6}$ and cognitive ${ }^{7}$ effects. Both because of increasing participation and the unique ability to study the body under long-term exercise stress, further study of ultraendurance events is warranted.

Past studies suggest that participation in ultraendurance events acutely reduces lung function. ${ }^{5,8,9}$ These studies demonstrated decreases in maximum voluntary ventilation at 12 -second ${ }^{9,10}$ and 30 -second ${ }^{8}$ maximum inspiratory/expiratory pressure $^{6}$ as well as peak expiratory flow and forced expiratory volume $\left(\mathrm{FEV}_{1}\right){ }^{11}$ Additionally, declines in hemoglobin, hematocrit, and red blood cells have been noted after the 100-km ultramarathon. ${ }^{12}$ Based on these reported changes, it is likely that capacity for oxygen delivery is impaired after ultraendurance performance. However, these data are reported from only ultramarathon events, and thus more information needs to be gathered on additional forms of ultraendurance competitions.

The study of mucosal immunity in conjunction with exercise is a topic of current interest because recent 
advances have made measurement of antimicrobial peptides and immunoglobulins in saliva more available. One of the primary analytes of interest has been secretory immunoglobulin A (IgA), the primary immunoglobulin in saliva that functions as part of the body's initial defense against invading microbes..$^{13,14}$ This dimeric molecule is produced in plasma cells that lie adjacent to salivary glands, from which it is excreted in a saliva flow rate-dependent fashion. ${ }^{15}$ Marathon and endurance performance have been shown to negatively affect salivary IgA. ${ }^{16-19}$ Although the response of salivary $\operatorname{IgA}$ is well characterized in regard to longduration exercise, other important components of mucosal immunity, such as salivary alpha amylase, require further study. ${ }^{20}$ Recent data from a multistage marathon demonstrated reductions in salivary IgA with concomitant increases in salivary alpha amylase. ${ }^{21}$ Although some studies of secretory $\operatorname{IgA}(\operatorname{sg} \mathrm{A})$ and other mucosal immune markers have been conducted in conjunction with ultraendurance events, more work is needed to develop a comprehensive understanding of how the varied length and composition of different events affect these markers. It has been suggested that subclasses of IgA in saliva, particularly sIgA type 1, are related to risk of infection in athletes. ${ }^{22}$ Subclasses of IgA in saliva have yet to be reported on in conjunction with ultraendurance events. Thus, sIgA type 1 was selected as a primary variable of interest for the present study along with standard measures of salivary IgA and alpha amylase.

The present study was undertaken on a novel ultraendurance race that was 36 hours in length and combined strength, endurance, and work capacity tasks. It was hypothesized that athletes who finished the event would demonstrate marked reduction in markers of mucosal immunity, lung function, and hematocrit whereas athletes who dropped out before finishing would have minimal to no change in similar measures.

\section{Materials and Methods}

\section{DESIGN AND STUDY POPULATIONS}

The present study was conducted during a 36-hour long endurance race. This race took place in the summer in the Midwestern United States. Participants were recruited on site before beginning the event. The experimental procedures were explained to all participants, and participants gave written informed consent before beginning the study. The study was reviewed and approved by the Institutional Review Board at the University of Louisiana at Lafayette. Data were collected in a repeated measures fashion at the start of the event and when the participant's effort concluded (either finishing at 36 hours or due to dropout).

\section{PARTICIPANTS}

Of the 20 competitors who registered for the event, 13 volunteered (12 male competitors, 1 female competitor) to be included in the investigation. Participants' weight and body fat percentage were determined via a Tanita body composition analyzer (Model BF522W; Tanita Corp, Arlington Heights, IL). The participants were asked to fill out the Leisure and Physical Activity Survey, an instrument developed in our lab to quickly assess physical activity patterns, before the event ${ }^{23}$ and had tympanic temperature collected at the check-in between event tasks in a manner reported in a previous study. ${ }^{6}$ On average, the participants reported 3 to 5 days, $>30$ minutes per session of both weightlifting and aerobic exercise. Details about the participants are in the Table. Seven participants completed the entire 36hour event and 6 competitors dropped out or were cut from the event before 24 hours.

\section{ULTRAENDURANCE EVENT}

The event was held on a private, wooded, rural farm in late summer. Before the event, the contestants are blinded to the composition of the tasks that are to be completed, although they are required to bring some of the supplies, such as sand, buckets, and an ax. The tasks to be completed generally are grouped into the following categories: running, long-distance weighted carries, strong-man type activities (deadlifts, Olympic lifts, overhead throws, farmers walks), chopping and carrying wood, calisthenics, and military-style marches. Each task must be completed and observed by a race official before the next can be started. The participants are not allowed to sleep during the event, and rest time between tasks is limited to a few minutes. Participants are allowed ad libitum water and snacks. Participants routinely check in at the race starting point during the event, and competitors who did not make sufficient progress

Table. Participant characteristics.

\begin{tabular}{lcl}
\hline Variable & Mean & $S D$ \\
\hline Age $(\mathrm{y})$ & 34.5 & 5.2 \\
Height $(\mathrm{cm})$ & 178 & 6 \\
Weight $(\mathrm{kg})$ & 78.0 & 7.4 \\
Body fat $\%$ & 11.4 & 2.8 \\
Average tympanic temperature $\left({ }^{\circ} \mathrm{C}\right)$ during event & 36.8 & 0.3 \\
\hline
\end{tabular}

$\mathrm{n}=12$ males; $\mathrm{n}=1$ female, given in mean $\pm \mathrm{SD}$.

$\mathrm{SD}$, standard deviation. 
through the tasks were dropped from the event at the 24hour mark.

\section{SALIVA COLLECTION AND DERMAL PUNCTURE}

Samples were collected before the race and immediately upon returning to the check-in after dropping out during an event, being cut from the event at the 24-hour mark, or upon event completion. The samples were gathered using a SalivaBio Oral Swab (Salimetrics, State College, PA) placed under the tongue for 2 minutes with the chin tipped downward. Before each collection, the swab was weighed using a portable digital scale that was calibrated in the field, and the final weight of the swab was determined again after collection. The change in weight (grams) was divided by the collection time (120 seconds) to determine salivary flow rate for each sample. Upon collection, samples were frozen on dry ice for transport and stored at $-35^{\circ} \mathrm{C}$ before analysis.

Dermal punctures performed in singlet at the fingertip were used to collect capillary blood before the event and again at dropout or completion. The blood was collected in a heparinized capillary tube and immediately centrifuged for 15 minutes in a microhematocrit centrifuge (Adams Micro-Hematocrit Centrifuge; Clay Adams, Parsippany, NJ). The centrifuged samples were read with a microhematocrit tube reader (Leica Biosystems, Richmond, VA).

\section{QUANTIFICATION OF SALIVARY BIOMARKERS}

Before analysis, saliva samples were thawed and centrifuged for 15 minutes and the supernatant collected for analysis. Salivary alpha amylase was quantified via a kinetic enzyme assay (Salimetrics) with a sample dilution factor of 1:200. A commercially available indirect competitive immunoassay (Salimetrics) was used to determine secretory IgA levels in saliva (1:5 dilution). Finally, a commercially produced enzyme-linked immunosorbent assay kit (Alpco Diagnostics, Salem, MA) was used to determine the level of secretory IgA type 1 (1:1000 dilution). Microplates were read on a kinetic microplate absorbance reader (BioTek Elx 808, Winooski, VT). Samples were analyzed in duplicate, and the average intraplate coefficient of variation was less than $5 \%$. After quantification, concentrations were controlled for salivary flow rate.

\section{PEAK FLOW AND FORCED EXPIRATORY VOLUME}

Peak expiratory flow $(\mathrm{L} / \mathrm{min})$ and $\mathrm{FEV}_{1}$ at 1 second were measured before the event and at dropout or completion using a MicroLife Peak Flow Meter (MicroLife USA,
Clearwater, FL). The device meets the standard for accuracy of the American Thoracic Society and has previously been used in research studies assessing $\mathrm{FEV}_{1} \cdot{ }^{24}$

\section{STATISTICAL ANALYSIS}

Data were first analyzed for normal distribution via Shapiro Wilk analysis. Nonnormal data were logtransformed before analysis. Analysis of variance (ANOVA) was used to examine average tympanic temperature by group (finisher, dropout). Repeated measures ANOVAs were used to assess change by time (pre, post) and by group (finisher, dropout). Statistical significance was set a priori at $\alpha<.05$. A statistical software package was used (JMP version 11.0 Pro; SAS Institute Inc., Cary, NC) with G*Power software to determine effect sizes. ${ }^{25}$

\section{Results}

\section{ANALYSIS OF NORMALITY}

Significant results of Shapiro Wilk tests $(P=.044$ and $P=.049$, respectively) for sIgA type 1 and alpha amylase expression rates revealed nonnormal distribution of these data. Therefore, these data were log transformed before further data analysis. All other measures were not found to deviate significantly from normal distribution $(P>.05)$.

\section{FINISHERS AND NONFINISHERS}

Race finishers were those who completed all 36 hours of the ultraendurance race. The nonfinishers were those who dropped out or were cut before the completion of the event ( 1 dropped out at 24 hours; remaining dropouts occurred between 12 and 20 hours; mean \pm SD $17 \pm 5.5$ hours).

\section{TYMPANIC TEMPERATURE}

Results of ANOVA analysis $\left(\mathrm{F}_{1,11}=0.458 ; P=.513\right)$ did not reveal an average difference in tympanic temperature across the race by group (finisher: $36.7 \pm 0.3^{\circ} \mathrm{C}$; dropout: $36.8 \pm 0.2^{\circ} \mathrm{C}$ ).

\section{HEMATOCRIT AND SALIVARY FLOW RATE}

Repeated measures ANOVA examining prerace to postrace changes in hematocrit among finishers and nonfinishers did not reveal significant main effects for time $\left(\mathrm{F}_{1,11}=0.219 ; P=.651\right)$ or interaction effects for group $\left(\mathrm{F}_{1,11}=0.027 ; P=.873\right)$. Mean prerace and postrace hematocrit levels were similar among finishers (pre: 45.3, post: 44.5) and nonfinishers (pre: 44, post: 43.6). 


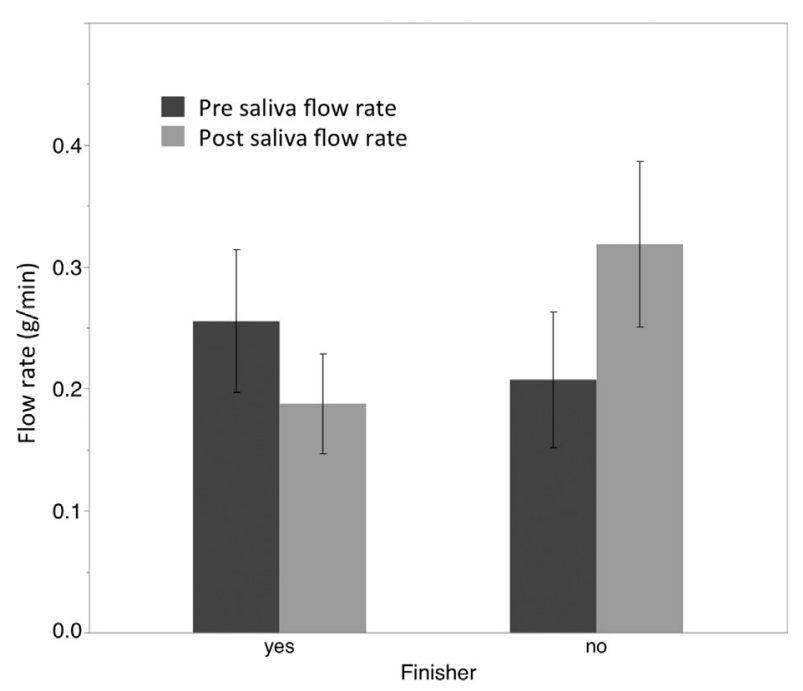

Figure 1. Graph showing changes in salivary flow rate pre- and postultraendurance race. $(*)$ denotes significant difference $(P<.05)$ from pre to post among group. Error bars represent \pm 1 standard error of the mean (SEM).

Similar analysis for salivary flow rate again did not reveal a main effect for time $\left(\mathrm{F}_{1,11}=0.389 ; P=.545\right)$; however, a significant interaction was noted for group by time $\left(\mathrm{F}_{1,11}=6.579 ; P=.026\right)$. Post hoc analysis revealed a significant increase in salivary flow rate among nonfinishers $(\mathrm{t}=2.18 ; P=.04$; effect size $[E S]=0.889)$ but not among finishers $(\mathrm{t}=-1.43$; $P=.101 ; \mathrm{ES}=.538)$, although a trend for reduced flow rate was noted (see Figure 1).

\section{SECRETORY IgA AND IgA TYPE 1}

Concentration values for both $\operatorname{sg} \mathrm{A}$ and $\operatorname{sIg} \mathrm{A}$ type 1 were first divided by salivary flow rate to determine expression rates for the immunoglobulins. Following this calculation, repeated measures ANOVA for SIgA expression rate did not reveal a main effect for time $\left(\mathrm{F}_{1,11}=0.23 ; P=.642\right)$ but did reveal a significant interaction effect for group by time $\left(\mathrm{F}_{1,11}=7.92\right.$; $P=.017)$. Post hoc analysis demonstrated a significant reduction in expression rate among finishers of the 36-hour event $(\mathrm{t}=-1.90 ; P=.05 ; \mathrm{ES}=0.717)$ and a significant increase in expression rate among those who dropped out or were stopped before 24 hours $(\mathrm{t}=2.03 ; P=.04 ; \mathrm{ES}=0.830$; Figure 2).

Repeated measures ANOVA for sIgA type 1 expression rate did not reveal a significant main effect for time $\left(\mathrm{F}_{1,11}=0.49 ; P=.500\right)$ or a significant interaction effect for time by group $\left(\mathrm{F}_{1,11}=1.33 ; P=.273\right)$. A significant trend in the data was not noted among the finishers for a reduction in $\operatorname{SIg}$ A type 1 expression rate $(\mathrm{t}=-1.07 ; P=.164 ; \mathrm{ES}=0.402$; see Figure 3$)$.

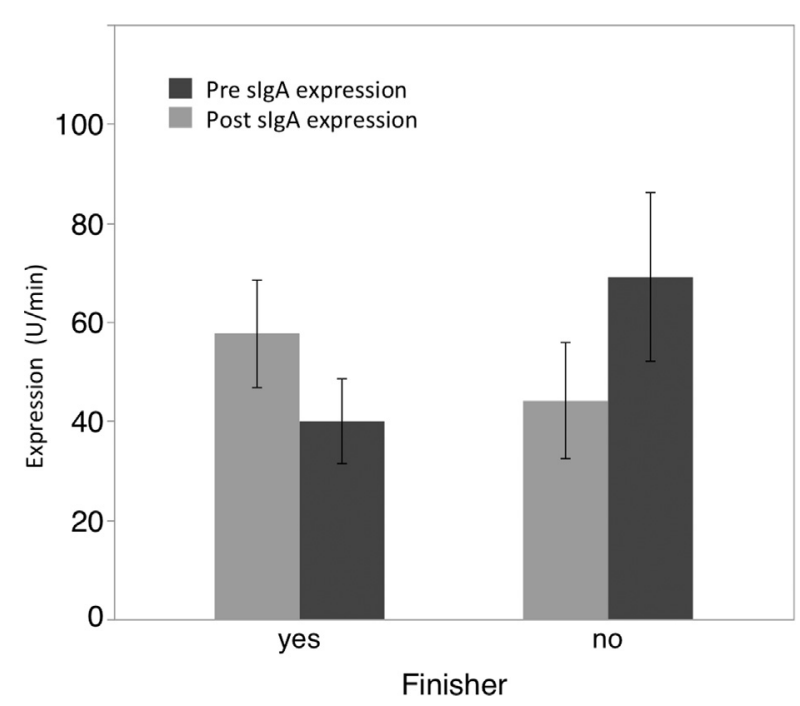

Figure 2. Graph showing changes in salivary $\operatorname{IgA}$ expression rate $(\mu \mathrm{g} / \mathrm{min})$ pre- and post-ultraendurance race. Error bars represent \pm 1 SEM.

\section{SALIVARY ALPHA AMYLASE}

Repeated measures ANOVA did not reveal a significant main effect for time $\left(\mathrm{F}_{1,11}=0.17 ; P=.692\right)$ when examining salivary alpha amylase expression nor a significant interaction effect for time by group $\left(\mathrm{F}_{1,11}=0.266 ; P=.619\right)$.

\section{PULMONARY TESTS}

Repeated measures ANOVA for peak flow did not reveal a significant main effect for time $\left(\mathrm{F}_{1,11}=0.01\right.$;

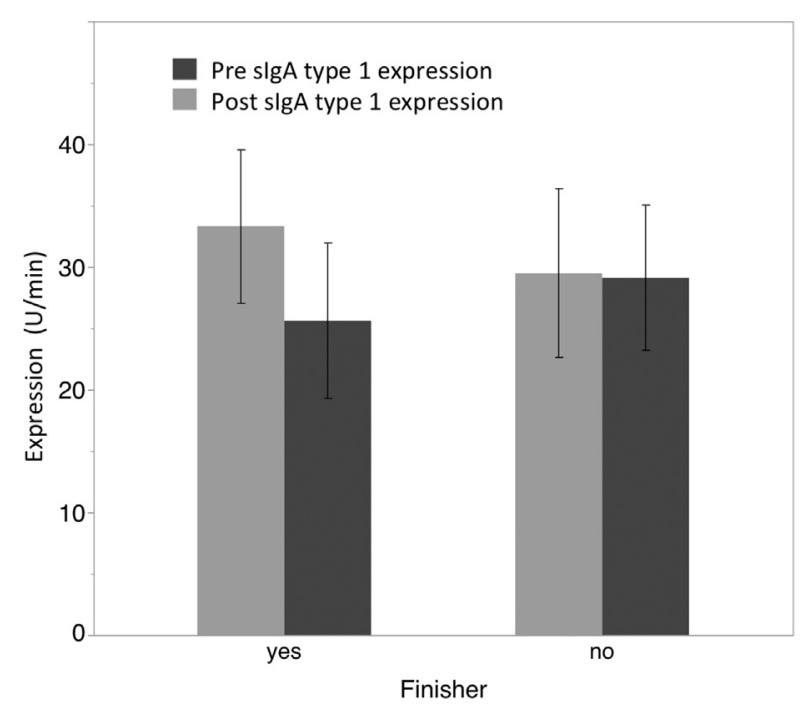

Figure 3. Graph showing changes in salivary IgA type 1 expression rate $(\mu \mathrm{g} / \mathrm{min})$ pre- and post-ultraendurance race. Error bars represent \pm 1 SEM. 


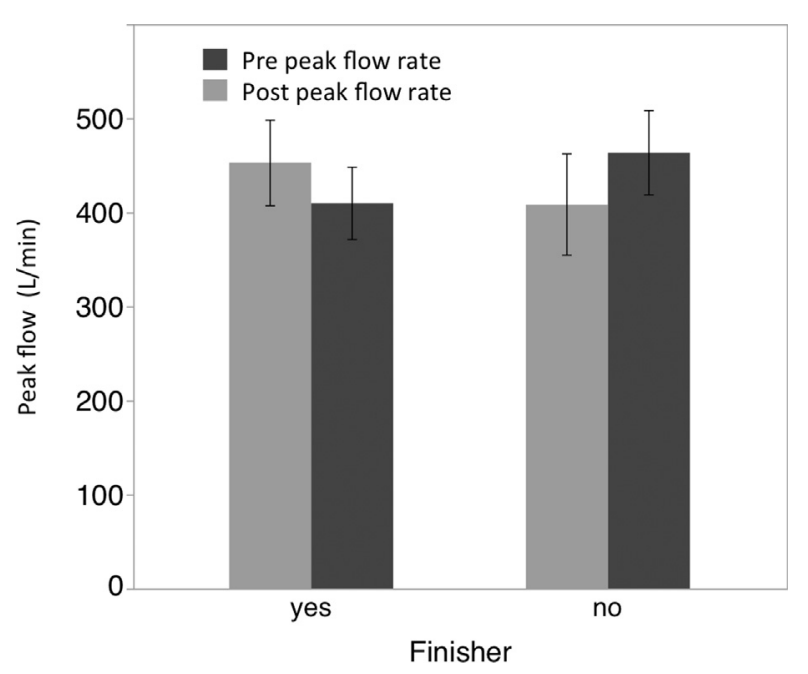

Figure 4. Graph showing changes in peak flow measurements (L/ $\min )$ pre- and post-ultraendurance race. Error bars represent \pm 1 one SEM.

$P=.946)$ but did demonstrate a significant interaction effect for finishers vs nonfinishers by time $\left(\mathrm{F}_{1,11}=4.55\right.$; $P=.05)$. Post hoc analysis demonstrated trends in the data for reductions (see Figure 4) in peak flow rate among finishers $(\mathrm{t}=-1.52 ; P=.09 ; \mathrm{ES}=0.533)$ and increases in peak flow rate among nonfinishers $(\mathrm{t}=1.49$; $P=.09 ; \mathrm{ES}=0.611$ ).

Analysis of $\mathrm{FEV}_{1}$ data did not reveal any significant main effects for time $\left(\mathrm{F}_{1,11}=1.21 ; P=.298\right)$ or interaction effects for finisher vs nonfinisher by time $\left(\mathrm{F}_{1,11}=1.80 ; P=.209\right)$.

\section{Discussion}

The present investigation extends the understanding of the effects of long-duration, ultraendurance type exercise on mucosal immunity and pulmonary function. What is unique about the present article is the examination of an event that requires 2 overnight periods of exercise without sleep. Furthermore, this study reports the differential responses among those athletes who completed all 36 hours of activity and those who did not make it past the 24-hour mark. Previous work examined the effects of 30 hours without sleep on the salivary $\operatorname{IgA}$ response to an acute bout of exercise. ${ }^{26}$ These authors did not report any changes in $\operatorname{sg} \mathrm{A}$ due to sleep deprivation alone in a crossover design. ${ }^{25}$ In the nonfinishers group for the present study, only 1 night of sleep deprivation was completed, which may in part explain why this group did not show a decline in sIgA. The significant decreases in total $\operatorname{sg} \mathrm{A}$ expression rate that were observed among the finishers of the race were consistent with previous findings for a 24-hour ultramarathon. ${ }^{21}$ It should be noted that recent work by Hucklebridge et $\mathrm{al}^{27}$ demonstrated a diurnal variation in $\operatorname{sIgA}$ in a small cohort of men. However, the acrophase (highest peak) was determined to be the morning, whereas our results suggest depressed levels of expression (race concluded at 07:00). Therefore, if a diurnal variation with higher levels in the morning is indeed present, the results from the present study may represent a robust finding of a decrease in secretion concomitant with an acrophase.

Additionally, Gill et $\mathrm{al}^{21}$ reported reduced salivary flow rates similar to those observed among the finishers of the present investigation; however, the authors also reported a significant increase in salivary alpha amylase activity, which was not found in the present study. The present study extends the knowledge surrounding salivary $\operatorname{IgA}$ and ultraendurance events to include events based upon both sleep deprivation and varied forms of exercise. Work needs to continue in these areas, as recent reviews by Orysiak et $\mathrm{al}^{28}$ on $\operatorname{sIg} \mathrm{A}$ and upper respiratory tract infection and by Walsh et $\mathrm{al}^{29}$ on exercise and immune function suggest that reductions in $\operatorname{IgA}$ are associated with increased risk of upper respiratory tract infection.

While most studies in the literature have focused on the dimeric molecule salivary $\operatorname{IgA}$, in the present study an additional immunoglobulin secretory $\operatorname{IgA}$ type 1 was assessed. Although no significant differences were revealed for this immunoglobulin, further work should be conducted in this area as this form of exercise might negatively affect the expression of this molecule. Further work will need to be conducted in this area, as secretory IgA type 1 was found to be important $\mathrm{t}^{22}$ and associated with reduced upper respiratory tract infection in a group of athletes.

Additionally, peak expiratory flow, $\mathrm{FEV}_{1}$, and salivary flow rate were examined pre- and postevent in the present study. The results of the study suggest a decline in peak expiratory flow among the completers of the 36hour event. Ross et $\mathrm{al}^{30}$ reported similar declines in peak expiratory flow immediately after marathon running. However, pulmonary function was slightly improved among the nonfinishers. This may be due to the initial effects of exercise on the competitors before the onset of fatigue. It has been shown that warm-up exercise is effective at improving respiratory function in athletes, ${ }^{31}$ so it could be speculated that completing the initial stages of the event may have provided benefit similar to a warm-up, but not enough stress to induce respiratory fatigue. Further research will be required to clarify the difference in the data from the nonfinishers. Additionally, salivary flow rate was not significantly reduced in finishers, but was significantly increased in nonfinishers. Although nonsignificant, the mean 
secretion rate was lower in the finishers at the conclusion of the race, similar to other reports in the literature. ${ }^{21}$ The increase in the nonfinishers is intriguing and again will require more research to understand.

\section{LIMITATIONS}

Although the present investigation provides unique information from a type of ultraendurance event that is not well represented in the literature, there are limitations. First, even though these races are increasing in popularity, the field size is still significantly smaller than an average marathon. Therefore, although the majority of the race participants agreed to be part of the study, the overall study population was small. Second, because of the event course and race design, the participants could not be observed for some periods. Due to these limitations, hematocrit could only be assessed in singlet. It also was not possible to determine the fluid and nutrient intake of the participants. However, based upon the effect sizes of the findings, the authors are confident that the data are representative of physiological differences among the participants. ${ }^{23}$

\section{Conclusions}

The present study suggests that ultraendurance races differentially affect markers of mucosal immunity and pulmonary function (as measured by peak flow) of finishers as compared with those who retire before the end of the race. Additionally, in the particular ultraendurance event studied, finishing the race resulted in declines in immune defense in the oral cavity, pulmonary function, and salivary flow rate. Ultraendurance athletes should be aware of these consequences and take steps to minimize their exposure to sources of upper respiratory tract infections in the hours after the race.

Acknowledgment: The authors would like to acknowledge and thank Gut Check Fitness, in particular Joe and Nicole Decker, for providing an opportunity for this study to be conducted.

Author Contributions: Study concept and design (DB, GRD, TP); acquisition of the data (DB, KAM, RA, TP); analysis of the data (DB, KAM, RA, GRD, TP); drafting of the manuscript (DB, RA, GRD); critical revision of the manuscript (DB, RA, GRD); and approval of final manuscript (DB, RA, GRD).

Financial/Material Support: None.

Disclosures Statement: None.

\section{References}

1. Hoffman MD, Wegelin JA. The Western States 100-mile endurance run: participation and performance trends. Med Sci Sports Exerc. 2009;4:2191-2198.
2. Hoffman MD, Ong JC, Wang G. Historical analysis of participation in the $161 \mathrm{~km}$ ultramarathons in North America. Int J Hist Sport. 2010;2:1877-1891.

3. Shoak MA, Knechtel B, Rüst CA, Lepers R, Roseman T. European dominance in multistage ultramarathons: an analysis of finisher rate and performance trends from 1992 to 2010. Open Access J Sports Med. 2013;4:9-18.

4. Casoni I, Borsetto C, Cavicchi A, Martinelli S, Conconi F. Reduced hemoglobin concentration and red cell hemoglobinization in Italian marathon and ultramarathon runners. Int J Sports Med. 1985;6:176-179.

5. Ker JA, Schultz CM. Respiratory muscle fatigue after an ultra-marathon measured as inspiratory task failure. Int $J$ Sports Med. 1996;17:493-496.

6. Wüthrich TU, Marty J, Kerherve H, Millet GY, Verges S, Spengler CM. Aspects of respiratory muscle fatigue in a mountain ultramarathon race. Med Sci Spots Exerc. 2015;47:519-527.

7. Davis GR, Ethredge CE, Marcus L, Bellar D. Prolonged sleep deprivation and continuous exercise: effects on melatonin, tympanic temperature, and cognitive function. Biomed Res Int. 2014;2014:781-863.

8. Blaber AP, Walsh ML, Carter JB, Seedhouse EL, Walker VE. Cardiopulmonary physiology and responses of ultramarathon athletes to prolonged exercise. Can J Appl Physiol. 2004;29:544-563.

9. Vernillo G, Rinaldo N, Giorgi A, et al. Changes in lung function during an extreme mountain ultramarathon. Scand J Med Sci Sports. 2015;25:e374-e380.

10. Warren GL, Cureton KJ, Sparling PB. Does lung function limit performance in a 24-hour ultramarathon? Respir Physiol. 1989;78:253-263.

11. Mahler DA, Loke J. Pulmonary dysfunction in ultramarathon runners. Yale J Biol Med. 1981;54:243-248.

12. Chiu YH, Lai JI, Wang SH, et al. Early changes of the anemia phenomenon in male 100-km ultramarathoners. J Chin Med Assoc. 2015;78:108-113.

13. Brandtzaeg P. Mucosal immunity: Induction, disseminations, and effector functions. Scan J Immunol. 2009;70: 505-515.

14. Bosch JA, Ring C, de Gues EJ, Veerman EC, Amerongen AV. Stress and secretory immunity. Int Rev Neurobiol. 2002;52:213-253.

15. Kugler J, Hess M, Haake D. Secretion of salivary immunoglobulin A in relation to age, saliva flow, mood states, secretion of albumin, cortisol and catecholamines in saliva. J Clin Immunol. 1992;12:45-49.

16. Laing SJ, Gwynne D, Blackwell J, Williams M, Walters R, Walsh NP. Salivary IgA response to prolonged exercise in a hot environment in trained cyclists. Eur J Appl Physiol. 2005;93:665-671.

17. Nieman DC, Dumke CL, Henson DA, et al. Immune and oxidative changes during and following the Western States Endurance Run. Int J Sports Med. 2003;24:541-547.

18. Nieman DC, Henson DA, Fagoaga OR, et al. Change in salivary $\operatorname{Ig}$ A following competitive marathon race. Int $J$ Sports Med. 2002;23:69-75. 
19. Tauler P, Martinez S, Moreno C, Martínez P, Aguilo A. Changes in salivary hormones, immunoglobulin A and C-reactive protein in response to ultra-endurance exercises. Appl Physiol Nutr Metab. 2014;39:560-565.

20. Papacosta E, Nassis GP. Saliva as a tool for monitoring steroid, peptide and immune markers in sport and exercise science. J Sci Med Sport. 2011;14:424-434.

21. Gill SK, Teixeira AM, Rama L, et al. Salivary antimicrobial protein responses during multistage ultramarathon competition conducted in hot environmental conditions. Appl Physiol Nutr Metab. 2013;38:977-987.

22. Gleeson M, Hall ST, McDonald WA, Flanagan AJ, Clancy RL. Salivary IgA subclasses and infection risk in elite swimmers. Immunol Cell Biol. 1999;77:351-355.

23. Bellar D, Judge LW, Petersen J, Bellar A, Bryan CL. Exercise and academic performance among nursing and kinesiology students at US colleges. J Educ Health Promot. 2014;3:9.

24. Wegienka G, Hasiec E, Boushey H, et al. Studying forced expiratory volume at 1 second over menstrual segments in asthmatic and non-asthmatic women: assessing protocol feasibility. BMC Res Notes. 2012;5:261.

25. Faul F, Erdfelder E, Lang A-G, Buchner A. G*Power 3: a flexible statistical power analysis program for the social, behavioral and biomedical sciences. Behav Res Method. 2007;39:175-191.

26. Ricardo JS, Cartner L, Oliver SJ, et al. No effect of a 30-h period of sleep deprivation on leukocyte trafficking, neutrophil degranulation and salivary $\operatorname{IgA}$ response to exercise. Eur J Appl Physiol. 2009;105:499-504.

27. Hucklebridge F, Clow A, Evans P. The relationship between salivary secretory immunoglobulin A and cortisol: neuroendocrine response to awakening and the diurnal cycle. Int J Psychophysio. 1998;31:69-76.

28. Orysiak J, Malczewska-Lenczowska J, Szygula Z, Pokrywka $\mathrm{A}$. The role of salivary immunoglobulin $\mathrm{A}$ in the prevention of the upper respiratory tract infections in athletes-an overview. Biol Sport. 2012;29:311-315.

29. Walsh NP, Gleeson M, Shephard RJ, et al. Position statement. Part one: Immune function and exercise. Exerc Immunol Rev. 2011;17:6-63.

30. Ross E, Middleton N, Shave N, George K, McConnell A. Changes in respiratory muscle and lung function following marathon running in man. J Sports Sci. 2008;26: 1295-1301.

31. Kesavachandran C, Shashidhar S. Respiratory function during warm-up exercise in athletes. Indian J Physiol Pharmacol. 1997;41:159-163. 